\title{
Surface behaviour of magnesium chloride-coated iron ore sinter
}

\author{
M. T. LARREA*, A. CORES, A. GUTIERREZ, A. FORMOSO \\ Centro Nacional de Investigaciones Metalurgicas, CSIC, Gregorio del Amo 8, 28040 Madrid, \\ Spain \\ J. L. G. FIERRO \\ Instituto de Catalisis y Petroleoquimica, CSIC, Serrano 119, 28006 Madrid, Spain
}

\begin{abstract}
The coating of sinter particles with magnesium chloride rendered a less reducible material at low temperature, and simultaneously enhanced mechanical strength. The joint use of scanning electron microscopy (SEM) and energy dispersive analyses of the X-rays (EDAX) emitted by the solid revealed the magnesium atoms to be almost uniformly distributed on the sinter surface. However, X-ray photoelectron spectroscopy (XPS) provided an extremely useful tool for understanding the chemical reaction, largely confined to the surface, when the sinter was heated at high temperatures. A model which assumes solid-state reaction between $\mathrm{MgO}$ and $\mathrm{Fe}_{2} \mathrm{O}_{3}$ to form a surface spinel-like $\mathrm{MgFe}_{2} \mathrm{O}_{4}$ compound has been proposed to describe that process in both salt-coated sinter and salt: physical mixture sinter preparations.
\end{abstract}

\section{Introduction}

It is generally agreed that reduction of iron ore concentrates and agglomerates in blast furnaces at low temperatures, e.g. $550^{\circ} \mathrm{C}$, causes a detrimental effect on the charge resistance with the subsequent permeability losses to the reducing gases and the increase of coke consumption [1]. Such a degradation lies essentially in the transformation, to a certain extent, of haematite, mostly secondary, to magnetite which is accompanied by a volume increase, thus giving rise to the appearance of structural strains in the agglomerates [2].

To minimize this difficulty, several alternatives have been put in practice. Among them the use of small amounts of other inorganic additives, was frequently used. Without doubt, the best performance of sinter during blast furnace operation is being achieved by impregnating those materials with diluted solutions of alkaline earth halides, i.e. $\mathrm{CaCl}_{2}, \mathrm{MgCl}_{2}$, etc. [3].

Upon heating to $600^{\circ} \mathrm{C}$, the added halides decompose through complex solid-state reactions, mainly confined to the sinter surface, and react with iron oxides to form mineralogical species able to inhibit the advance of haematite to magnetite.

Many efforts have recently been made to understand the inhibition of the sinter degradation after spraying or impregnating the iron ore sinter with dilute solutions of calcium, or magnesium halides [4]. However, to date no convincing explanation has been put forward. It is, therefore, the purpose of this work to give experimental evidence for the inhibition of the reduction of haematite to magnetite and also to propose a model to account for this phenomenon. For this two working hypotheses have been used: (i) alkalineearth halide favours the shift of the Boudouard

*Author to whom all correspondence should be addressed. reaction to the formation of carbon, and (ii) a solid state reaction between halide and haematite. To confirm the first hypothesis, the reduction of the sinter was conducted under a hydrogen gas stream in an $\mathrm{MgCl}_{2}$ treated sinter bed, whereas a detailed X-ray photoelectron spectroscopic (XPS) study was carried out either on physically mixed $\left(\mathrm{MgCl}_{2}+\right.$ sinter $)$ or on $\mathrm{MgCl}_{2}$-impregnated sinter samples.

\section{Experimental procedure}

Three different industrially available iron ores, $\mathrm{A}_{1}, \mathrm{~A}_{2}$ and $A_{3}$, were used in the present study. Their chemical composition and basicity index are summarized in Table I. Aliquots of these samples were coated with magnesium chloride either by aqueous impregnation or by physical mixture. Salt-coated magnesium granules were prepared by impregnating the raw sinter with a $10 \% \mathrm{MgCl}_{2}$ solution for $3 \mathrm{~h}$, then drying at $110^{\circ} \mathrm{C}$. These samples will be designated $\mathbf{B}_{1}, \mathbf{B}_{2}$ and $\mathbf{B}_{3}$.

Another $\mathrm{MgCl}_{2}$ : physical mixture sinter was also prepared by mixing the dry components in a blender. This last preparation will be designated $\mathrm{B}_{4}$.

Reduction experiments were conducted according to the ISO standard test [5]. The procedure and equipment are extensively detailed in that test. It basically consists in the reduction at $950^{\circ} \mathrm{C}$ of a static bed of the iron ore sinter, by a $30 \%(\mathrm{vol} / \mathrm{vol}) \mathrm{CO}: \mathrm{N}_{2}$ (151 (STP)/min) mixture. The reduction index usually obtained is the reduction rate at a $40 \%$ reduction of the sample $(\mathrm{d} R / \mathrm{d} t)_{40}$. The final reduction degree of the samples is obtained by determining the amount of oxygen already combined with iron from chemical analysis before and after reduction, according to the equation

$$
R=\left(\mathrm{O}_{\mathrm{T}}-\mathrm{O}_{\mathrm{F}}\right) / \mathrm{O}_{\mathrm{T}} \times 100
$$


TA BLE I Chemical analysis (wt \%) of raw sinter samples

\begin{tabular}{lcccccccccc}
\hline Sample & $\mathrm{Fe}_{\mathrm{T}}$ & $\mathrm{Fe}^{2+}$ & $\mathrm{CaO}$ & $\mathrm{MgO}$ & $\mathrm{Al}_{2} \mathrm{O}_{3}$ & $\mathrm{SiO}_{2}$ & $\mathrm{MnO}$ & $\mathrm{Na}_{2} \mathrm{O}$ & $\mathrm{K}_{2} \mathrm{O}$ & $\begin{array}{c}\mathrm{CaO}^{2}+\mathrm{MgO}^{*} \\
\mathrm{SiO}_{2}+\mathrm{Al}_{2} \mathrm{O}_{3}\end{array}$ \\
\hline $\mathrm{A}_{1}$ & 56.32 & 8.06 & 6.86 & 1.65 & 2.21 & 6.01 & 1.16 & 0.051 & 0.205 & 1.03 \\
$\mathrm{~A}_{2}$ & 56.98 & 7.98 & 8.86 & 2.65 & 1.15 & 6.14 & 0.72 & 0.070 & 0.048 & 1.58 \\
$\mathrm{~A}_{3}$ & 57.63 & 7.63 & 8.07 & 1.23 & 1.72 & 5.66 & 1.21 & 0.065 & 0.097 & 1.26 \\
$\mathrm{~B}_{1}$ & 56.30 & 8.20 & 7.02 & 1.77 & 2.11 & 6.00 & 1.15 & 0.035 & 0.173 & 1.08 \\
$\mathrm{~B}_{2}$ & 56.31 & 8.39 & 9.10 & 2.79 & 1.10 & 6.23 & 0.72 & 0.094 & 0.051 & 1.62 \\
$\mathrm{~B}_{3}$ & 57.49 & 7.60 & 7.84 & 1.32 & 1.67 & 5.92 & 1.15 & 0.061 & 0.120 & 1.21 \\
\hline
\end{tabular}

* Basicity index.

where $\mathrm{O}_{\mathrm{T}}$ and $\mathrm{O}_{\mathrm{F}}$ are the overall and final oxygen amounts, respectively, in the samples.

Low-temperature degradation tests (RDI) were carried out according to the ISO standard test [6]. Briefly it consists of the following steps. A $500 \mathrm{~g}$ sinter sample is heated within a stainless steel reactor $(7.5 \mathrm{~cm}$ diameter $\times 35.0 \mathrm{~cm}$ long) up to $550^{\circ} \mathrm{C}$ in a dry nitrogen flow (151 (STP) $/ \mathrm{min})$ and then stabilized for $0.5 \mathrm{~h}$ in a $30 \%$ (vol $/ \mathrm{vol}$ ) $\mathrm{CO}: \mathrm{N}_{2}$ gas mixture flow. After cooling to room temperature in a nitrogen atmosphere, the abrasion test was performed in a $20 \mathrm{~cm}$ long $\times 13 \mathrm{~cm}$ diameter drum at a rate of 30 turns per minute for $0.5 \mathrm{~h}$. Finally, the product was sized, and the fraction with sizes below $3 \mathrm{~mm}$ was taken as the RDI index.

$\mathrm{X}$-ray powder diffraction (XRD) patterns were obtained with a type PW 1010 Philips unit with nickel filtered $\mathrm{Cu} K \alpha$ radiation $(\lambda=0.1582 \mathrm{~nm})$ and using a Debye-Scherrer powder camera type PW 1024. Scanning electron micrographs (SEM) were taken with a Jeol $\times 50$ electron microscope at an accelerating voltage of $20 \mathrm{kV}$ on $2 \mathrm{~mm}$ thick pelleted samples. Good resolution was obtained at magnifications of $\times 600$ to $\times 900$. The space distribution of a given element was obtained by imaging the $K \alpha$ radiation of the atom of interest.

X-ray photoelectron spectra (XPS) of samples were recorded on a Leybold Heraeus LHS 10 spectrometer interfaced to a data station which allowed spectra accumulation. The X-ray tube of the spectrometer was provided with an aluminium anode $(h v=1486.6 \mathrm{eV})$ operated at $120 \mathrm{~W}$. The kinetic energy of the electrons emitted by the samples was measured on a hemispherical energy analyser (HEA) at a pass energy of $50 \mathrm{eV}$. The residual pressure within the analysis chamber was below $8.3 \times 10^{-12} \mathrm{~atm}$. The powdered samples were first pressed into small $8 \mathrm{~mm}$ diameter cylinders and then mounted on a long rod which allowed fast entry into the analysis chamber. To eliminate sample charging responsible for the XPS line broadening and the shift of element peaks to higher binding energy (BE), CIS photoemission at $284.6 \mathrm{eV}$ was considered as reference. The surface composition of the sample was determined using elemental sensitivity factors and the peak area intensities recorded for each element present in the sample.

\section{Results}

\subsection{Kinetics and equilibrium of reduction}

Kinetic reduction curves by $\mathrm{CO}$ under isothermic conditions $\left(950^{\circ} \mathrm{C}\right)$ for three untreated sinter samples $\left(\mathrm{A}_{1}\right.$, $A_{2}, A_{3}$ ) and for their corresponding magnesium chloride-coated partners $\left(B_{1}, B_{2}, B_{3}\right)$ are summarized in Fig. 1. From these results, it is clear that the reduction process is fast enough as measured by the relatively short times of $\sim 100$ min required to achieve 80 to $90 \%$ overall oxygen removal, whatever the supplier, and hence the history of preparation of the sinter samples. For a better comparison of the samples, the reduction rate at a $40 \%$ overall oxygen removal, $(\mathrm{d} R / \mathrm{d} t)_{40}$, and the reduction degree after $60 \mathrm{~min}$ from the beginning of reduction $\left(R_{60}\right)$, were calculated and are summarized in Table II for both clean (series A) and salt-coated (series B) samples. As can be observed, both $(\mathrm{d} R / \mathrm{d} t)_{40}$ and $R_{60}$ parameters depend only slightly on the type of sinter samples. An interesting
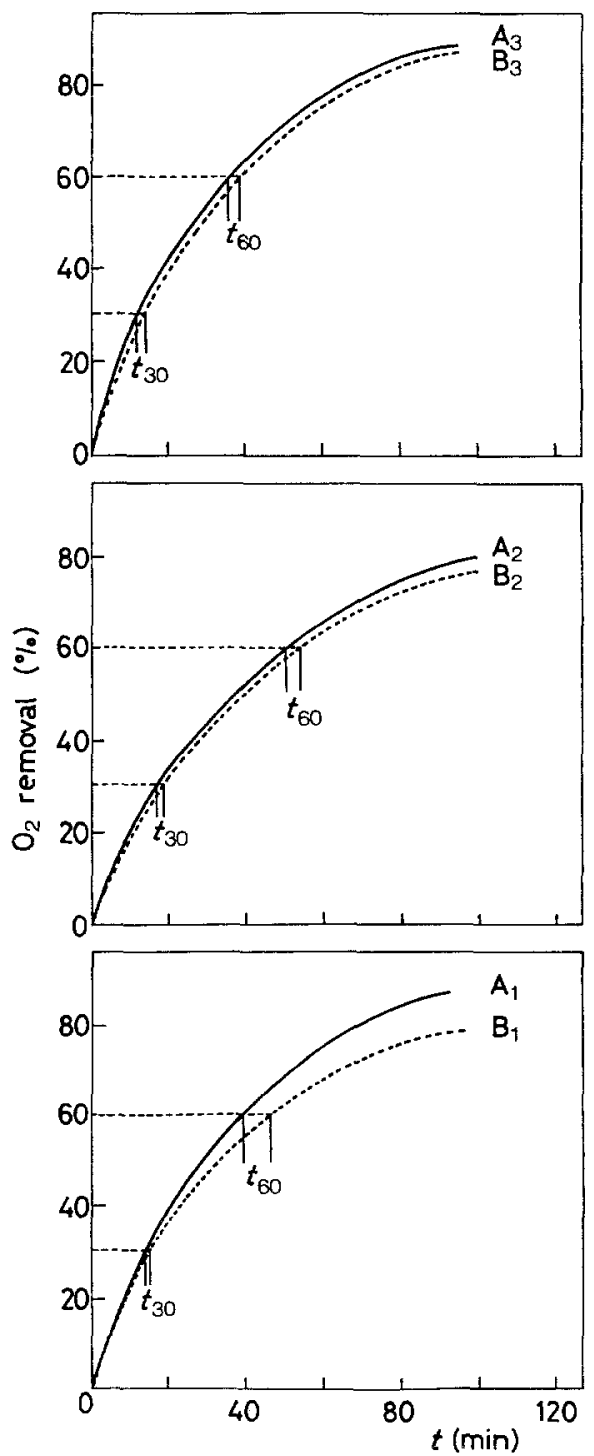

Figure $l$ Kinetic reduction curves at $900^{\circ} \mathrm{C}$ in a reducing $(\mathrm{CO})$ atmosphere for three sinter samples. Full lines denote uncoated raw sinter, and dashed lines correspond to salt-coated sinter. 
TABLE II Reduction parameters and RDI index of sinter samples

\begin{tabular}{lllll}
\hline Sample & $\begin{array}{l}\text { Reduction rate, } \\
(\mathrm{d} R / \mathrm{d} t)_{40}\left(\% \mathrm{O}_{2} \min ^{-1}\right)\end{array}$ & $\begin{array}{l}\text { Extent of reduction, } \\
R_{60}(\%)\end{array}$ & $\begin{array}{l}\mathrm{RDI} \\
(\%<3 \mathrm{~mm})\end{array}$ & $\mathrm{Fe}^{2+}(\%)$ \\
\hline $\mathrm{A}_{1}$ & 1.37 & 75.31 & 35.61 & 12.6 \\
$\mathrm{~A}_{2}$ & 1.02 & 67.22 & 27.34 & 12.5 \\
$\mathrm{~A}_{3}$ & 1.43 & 78.97 & 35.54 & 9.51 \\
$\mathrm{~B}_{1}$ & 1.12 & 69.50 & 1.57 & 8.32 \\
$\mathrm{~B}_{2}$ & 0.99 & 64.93 & 3.32 & 8.47 \\
$\mathrm{~B}_{3}$ & 1.34 & 76.37 & 2.3 & 6.70 \\
\hline
\end{tabular}

phenomenon to be examined is the inhibiting effect of magnesium salt on the reduction behaviour of the oxidic species, and especially of $\mathrm{Fe}^{2+}$, in salt-coated sinter samples (see Table II). The chemical modification, largely confined to the sinter surface, implies a noticeable improvement in the mechanical properties of aggregates as revealed by the drastic decrease of the RDI index (compare data for the untreated A series and for the salt-coated B series in Table II). A simple interpretation of this phenomenon will be depicted below on the basis of the magnesium and/or iron surface composition $(s)$ as revealed by the X-ray photoelectron spectroscopy.

\subsection{Microscopic and microanalytical data}

In order to understand the role played by magnesium halide on the mechanical strength of sinter to degradation, a microscopic and microanalytic (SEM-EDAX) study of the sinter particles subjected to different treatments has been carried out. For this purpose, an untreated $A_{1}$ raw sample and its corresponding saltcoated partner $B_{1}$ sample were used.

X-ray diffraction (XRD) patterns of both prepara-
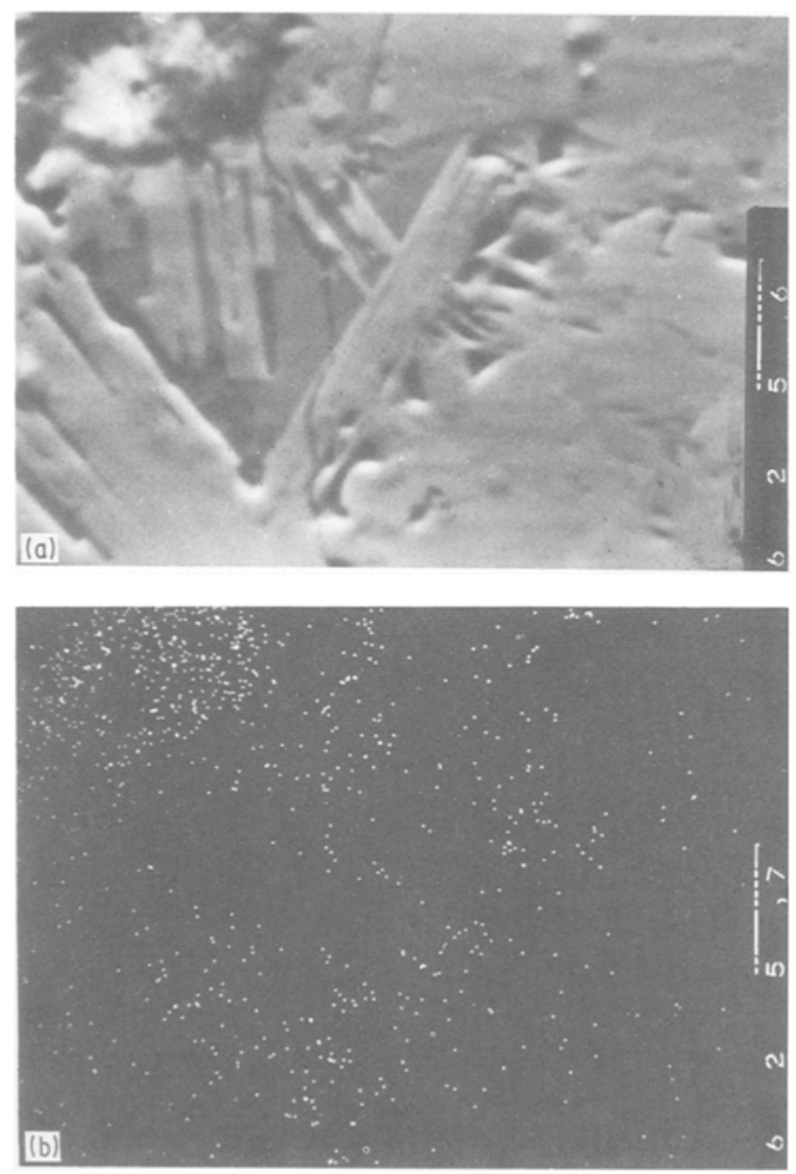

tions were essentially the same, with the only exception that the diffraction line at $2 \theta=47.2^{\circ}$ corresponding to the reflection of $\mathrm{Fe}_{3} \mathrm{O}_{4}$ species was slightly more attenuated in sample $B_{1}$ than in sample $A_{1}$. In order to determine whether the amount of magnetite had been altered by the magnesium halide coating, the magnetic susceptibilities were measured for both untreated $A_{1}$ and salt-coated $B_{1}$ samples. The amounts of equivalent magnetite thus determined (Gouy method) were 40.5 and $40.46 \%$ for samples $A_{1}$ and $B_{1}$, respectively. It must be emphasized that the dilution effect by the $\mathrm{MgCl}_{2}$ addition was considered for $\mathrm{B}_{1}$ preparation in that calculation.

Noticeable changes either in texture or location of elements in the sinter particles were revealed by the joint use of SEM-EDAX analysis. In a gross observation with the optical microscope, the salt-coated sample $B_{1}$ showed an unexpected higher proportion of ferrites than that on sample $A_{1}$. As observed on a relatively flat and low porous surface (Fig. 2a), a possible attack of ferrites by the magnesium halide might be expected; however, the mapping of chlorine atoms (Fig. 2b) and of magnesium (Fig. 2c) (obtained by imaging the $K \alpha$ emission of these elements), indicated that chlorine atoms are mainly localized in the porous regions of the sinter (whereas magnesium is more uniformly distributed). The working hypothesis adopted as a possible explanation is that during heating of the impregnate a fraction of the halide can be decomposed by water (or hydroxyl groups), thus generating $\mathrm{HCl}$ in the gas-phase and $\mathrm{MgO}$ which remain highly disperse and in intimate contact with the sinter particles. The extent of such decomposition

Figure 2 (a) Scanning electron micrograph $(\times 1248)$ of salt-coated sample $\mathrm{B}_{1}$. (b) and (c) Mapping of the $\mathrm{ClK \alpha}$ and $\mathrm{Mg} K \alpha$ emissions, respectively, from the same field area as in (a).

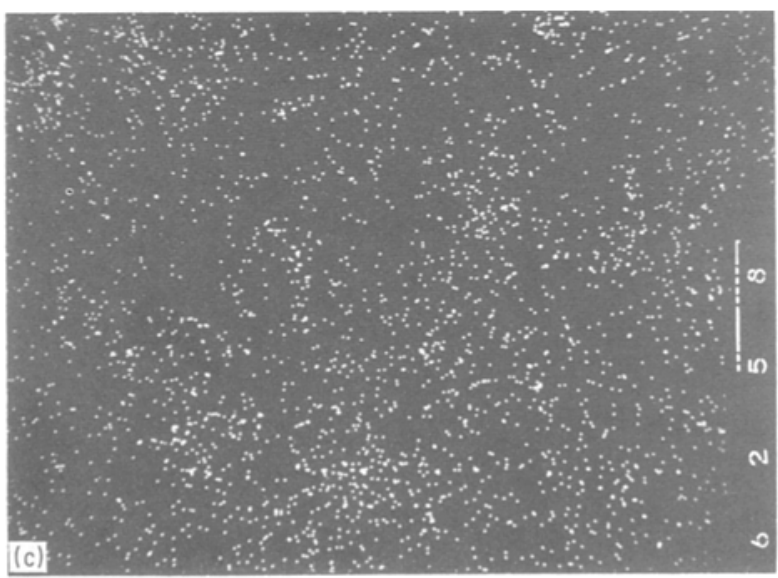



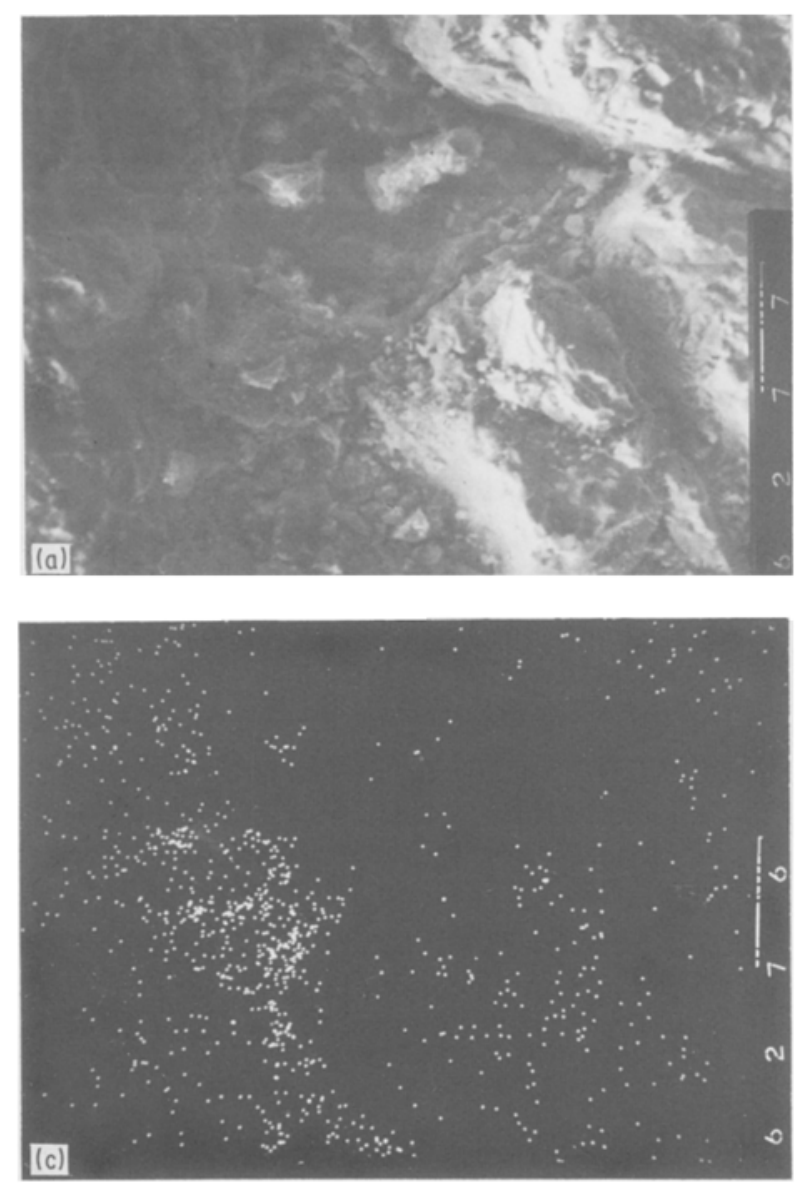

is moderate because rather short times and relatively low pretreatment temperatures were used. As described below in Section 3.3, the halide decomposition in the absence of water is strongly inhibited in an $\mathrm{MgCl}_{2}$ : sinter physical mixture up to $\sim 500^{\circ} \mathrm{C}$.

The texture of a sinter sample subjected to the degradation test (RDI) is substantially different to that observed in the fresh preparation (Fig. 3a). In this case, porosity is largely developed and the presence of chlorine and of magnesium, especially in those porous regions, is also patent (Fig. 3b). It must be emphasized that an important fraction of magnesium was still present in the raw sinter; consequently the preferential location of magnesium in the pores is not so clear as in the case of chlorine. The fact that the remaining chlorine (Fig. 3b) and magnesium (Fig. 3c) distributions run essentially parallel can be taken as indicative that in such conditions they should be associated as $\mathrm{MgCl}_{2}$. Possible redistribution of the salt during the RDI test cannot be fully excluded because the vapour pressure of $\mathrm{MgCl}_{2}$ at $550^{\circ} \mathrm{C}$ begins to be important (melting point $712^{\circ} \mathrm{C}$ ). As stated below, such a redispersion was indeed observed in an $\mathrm{MgCl}_{2}$ : physical mixture sinter subjected to increasing temperatures (cf. Fig. 7). Only temperatures as high as that involved in the ISO test of reduction $\left(950^{\circ} \mathrm{C}\right)$ rendered chlorinefree sinter particles.

\subsection{X-ray photoelectron analysis}

For a better understanding of the processes largely confined to the surface of sinter aggregates when exposed to a reducing (CO) atmosphere, a detailed study by XPS has been carried out on a salt-coated

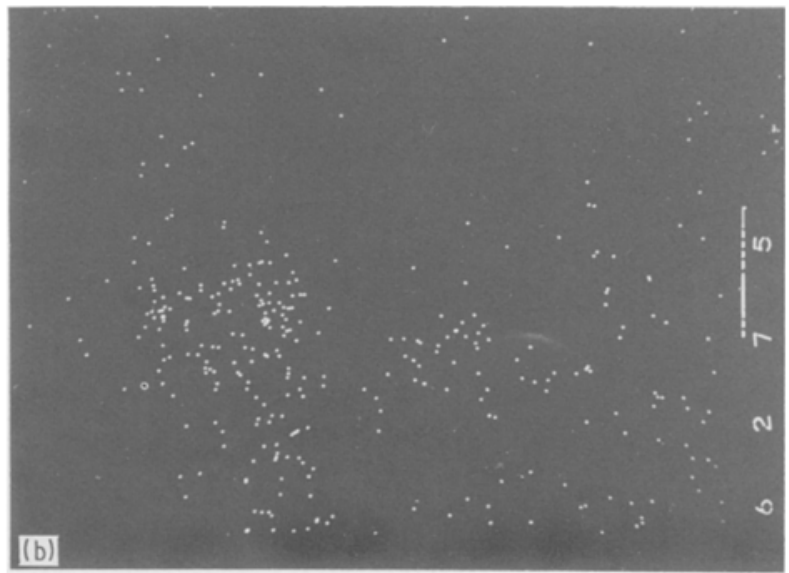

Figure 3 (a) Scanning electron micrograph $(\times 384)$ of salt-coated sample $\mathrm{B}_{1}$ after the RDI treatment. (b) and (c) Mapping of the $\mathrm{Cl} K \alpha$ and $\mathrm{MgK} \alpha$ emissions, respectively, from the same field area as in (a).

sinter sample. As stated above, and in agreement with published work, it has been shown that noticeable enhancement of the mechanical strength of sinter particles can be easily achieved by impregnating the sinter with aqueous solutions of alkaline or alkalineearth halides. Detailed work conducted in our laboratory showed that almost the same properties would be attained with a physical mixture of the halide and sinter particles. To account for this, an $\mathrm{MgCl}_{2}$ : physical mixture sinter was prepared and pretreated subsequently in a reducing $(\mathrm{CO})$ atmosphere in the temperature range 25 to $550^{\circ} \mathrm{C}$. For comparison purposes, another salt-coated sample prepared by conventional wet impregnation was also analysed.

\subsection{C1S levels}

Fig. 4 shows the core level signals for the $\mathrm{C} 1 \mathrm{~S}$ for the $\mathrm{MgCl}_{2}$ : physical mixture sinter pretreated in the 25 to $550^{\circ} \mathrm{C}$ temperature range (spectra a to $\mathrm{g}$ ), and for a conventionally impregnated sample (spectrum $\mathrm{g}^{\prime}$ ). As can be seen, a photoemission peak at $284.6 \mathrm{eV}$, associated with surface contamination, is common to all the spectra, and another line shifted $2.8 \mathrm{eV}$ toward higher binding energies (BE) is also observed in those samples pretreated at the lowest temperatures (spectra a to c). In the sample pretreated at ambient temperature this latter peak becomes more intense than that of contamination; its intensity decreases drastically at increasing pretreatment temperatures but it is not fully removed even at the highest temperature. It must be noted that spectra $\mathrm{c}$ to $\mathrm{g}^{\prime}$ show asymmetric lefthand wings due to the contribution of carbon species responsible for the $\mathrm{C} 1 \mathrm{~S}$ photoemission at higher $\mathrm{BEs}$. This last peak is characteristic of $\mathrm{C}=\mathrm{O}$ species, arising presumably from the atmospheric $\mathrm{CO}_{2}$ chemisorbed on the basic salt-coated sinter surface. Such an assignment is consistent with the work done on simple carbon-containing model compounds $[7,8]$ or on coal surfaces. Possible contribution to this high BE shoulder arising from the shake-up satellites associated with conjugated carbon structures may be excluded, because their abundance must be very low [9].

\section{5. $\mathrm{Mg} 1 \mathrm{~S}$ level}

Photoelectron spectra of the Mg $1 \mathrm{~S}$ core level of the 


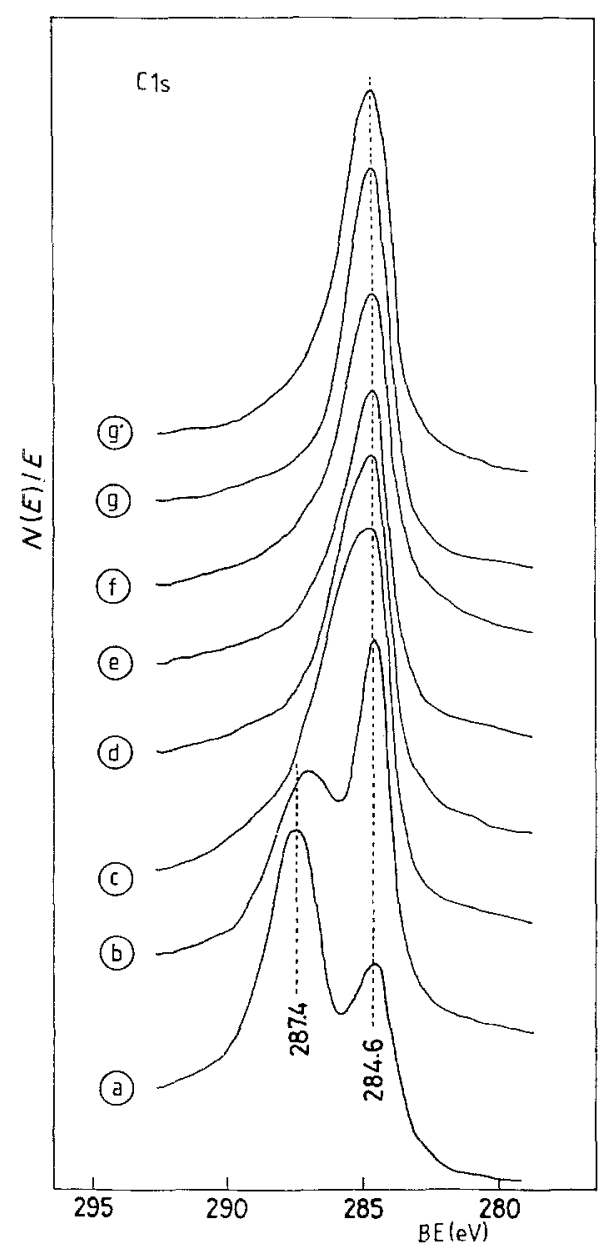

Figure $4 \mathrm{C} 1 \mathrm{~S}$ core level signals of a $\mathrm{MgCl}_{2}$ : physical mixture pretreated at different temperatures: (a) room temperature; (b) $100^{\circ} \mathrm{C}$; (c) $200^{\circ} \mathrm{C}$; (d) $330^{\circ} \mathrm{C}$; (e) $400^{\circ} \mathrm{C}$; (f) $490^{\circ} \mathrm{C}$; (g) $550^{\circ} \mathrm{C}$; and (g') of a salt-coated sinter prepared by conventional wet impregnation and pretreated at $550^{\circ} \mathrm{C}$.

$\mathrm{MgCl}_{2}$ :physical mixture sinter pretreated in a reducing (CO) atmosphere in the 25 to $550^{\circ} \mathrm{C}$ temperature range (spectra a to $\mathrm{g}$ ) and of a salt-coated sample prepared by conventional impregnation are shown in Fig. 5. The $\mathrm{BE}$ value of $50.9 \mathrm{eV}$ was essentially the same for all preparations, but the intensity varied substantially. In this respect, it is important to keep in mind that the $\mathrm{Mg} 1 \mathrm{~S}$ core level intensities are not comparable because the number of accumulations also varied. An inspection of the spectra showed that the full width at half maxima (FWHM) of the Mg $1 \mathrm{~S}$ level was not constant, e.g. it increased with increasing temperature. To account for this, the FWHM have been measured and plotted in Fig. 6 as a function of pretreatment temperature. As can be seen, the FWHM did not essentially vary at temperatures below $330^{\circ} \mathrm{C}$; it increased, however, at higher temperatures, reaching its maximum value at $550^{\circ} \mathrm{C}$. Such an increase might be taken as indication of the appearance of new magnesium-containing species at the surface of sinter particles.

\subsection{Fe $2 p$ levels}

Photoelectron spectra of the $\mathrm{Fe} 2 \mathrm{p}_{3 / 2}$ and $\mathrm{Fe} 2 \mathrm{p}_{1 / 2}$ levels of the $\mathrm{MgCl}_{2}$ physical mixture sinter pretreated in a reducing $(\mathrm{CO})$ atmosphere in the temperature range 25 to $550^{\circ} \mathrm{C}$ (spectra a to g), and of a salt-coated sinter sample prepared by conventional impregnation

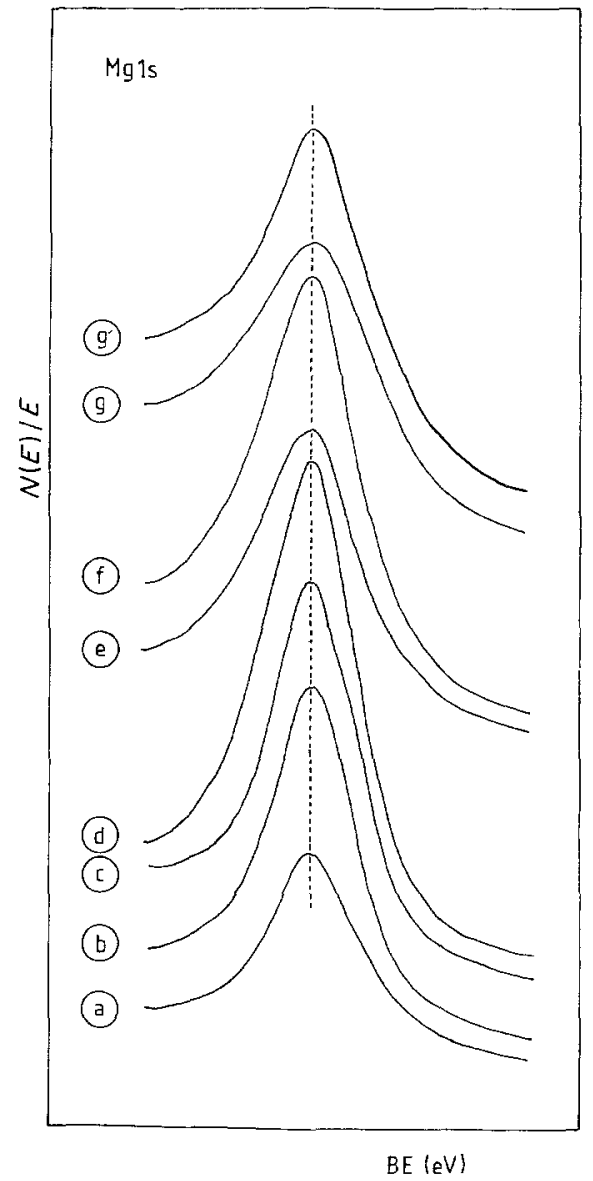

Figure $5 \mathrm{Mg} 1 \mathrm{~S}$ core level signals of a sinter sample. Preparation and pretreatments were the same as in Fig. 4.

(spectrum g') are given in Fig. 7. Above $100^{\circ} \mathrm{C}$, the $\mathrm{BE}$ values of 710.9 and $724.8 \mathrm{eV}$ for the $\mathrm{Fe} 2 \mathrm{p}$ doublet were roughly the same whatever the pretreatment, and the small differences of $\sim 0.3 \mathrm{eV}$ were within experimental error. Note that the $\mathrm{BE}$ value of the $\mathrm{Fe} 2 \mathrm{p}$ doublet closely corresponds to that reported in the literature for $\alpha \mathrm{Fe}_{2} \mathrm{O}_{3}[10-13]$. The presence of $\alpha-\mathrm{Fe}_{2} \mathrm{O}_{3}$ phase in the sinter particles is expected because this phase is the most common iron oxide, with the more uniform corundum structure, in which the oxygen ions adopt a hexagonal-close-packed arrangement and the $\mathrm{Fe}^{3+}$ ions are distributed throughout twothirds of the octahedral sites generated in this structure. Another important fact to be taken into account is that the sample pretreated at $400^{\circ} \mathrm{C}$ (spectrum e) displays the clearest shake-up lines which decline again at higher temperatures (spectra $f$ to $g^{\prime}$ ). This can be due to a partial transformation of $\alpha-\mathrm{Fe}_{2} \mathrm{O}_{3}$ in

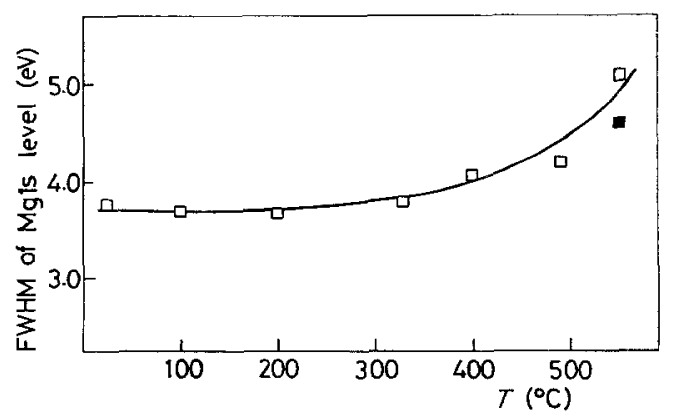

Figure 6 Dependence of the FWHM of Mg $1 \mathrm{~S}$ core level signals and the pretreatment temperatures for ( $\mathbf{m})$ a $\mathrm{MgCl}_{2}$ : physical mixture sinter, and $(\square)$ for conventionally impregnated sinter sample. 


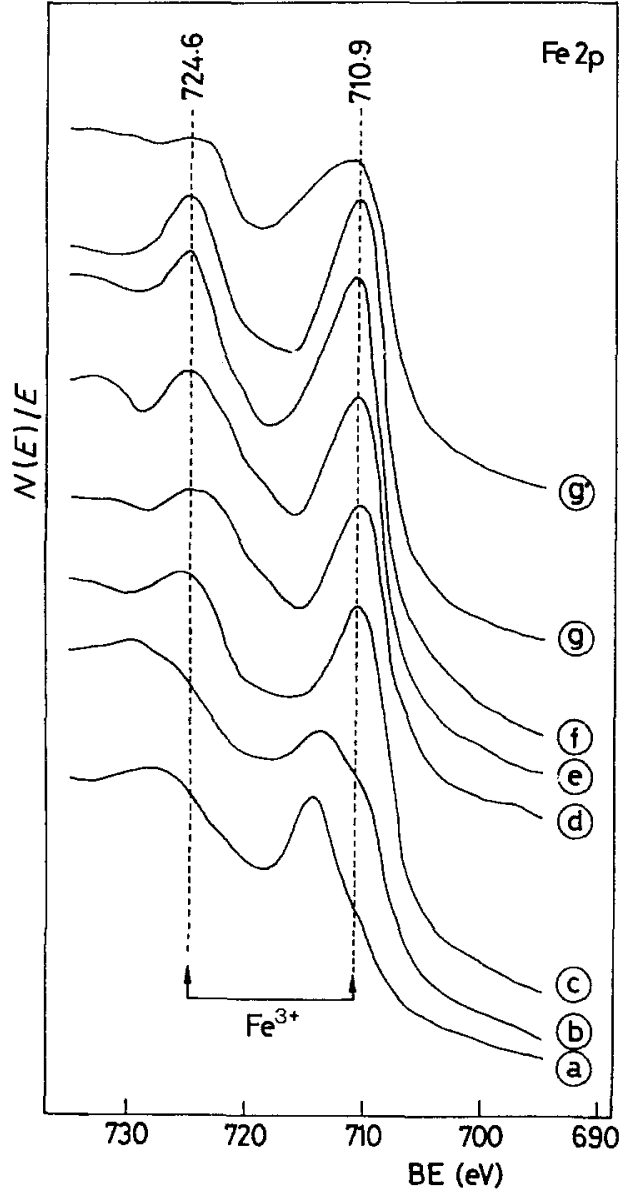

Figure $7 \mathrm{Fe} 2 \mathrm{p}$ core level signals of a sinter sample. Preparation and pretreatments were the same as in Fig. 4.

magnetite by $\mathrm{CO}$ and, therefore, decreasing the number of $\mathrm{Fe}^{3+}$ responsible for those shake up lines.

When samples were pretreated in the temperature range 25 to $100^{\circ} \mathrm{C}$ (spectra a and $b$ ) there is an important shift of the Fe 2p doublet towards higher BE. This is probably due to an enhancement of both multiplet splitting and shake-up which are known to occur in high-spin iron oxides having a formal oxidation number of three, containing an excess of chemisorbed or physically adsorbed water [14, 15].

As an approach to a better understanding of the relative abundance of magnesium and chlorine atoms on the surface of sinter particles, the $\mathrm{M} / \mathrm{O}(\mathrm{M}=\mathrm{Cl}$ or $\mathrm{Mg}$ ) ratios have been calculated and are represented in Fig. 8 as a function of temperature. For this calculation, the sensitivity factors, taking $f_{1 \mathrm{~S}}=1$ as standard according to Wagner et al. [16], have been used.

As shown in Fig. 8 the surface concentration of chlorine atoms increased with increasing temperature, reaching a maximum at $\sim 500^{\circ} \mathrm{C}$ and then drastically decreasing. A similar behaviour was found for magnesium, although the maximum was smoother than in the case of chlorine. Finally, small $\mathrm{M} / \mathrm{O}$ ratios were found in a conventionally wet impregnated salt-coated sinter sample pretreated in a reducing (CO) atmosphere at $550^{\circ} \mathrm{C}$.

\section{Discussion}

\subsection{The role of the halide}

The coating of sinter particles by magnesium chloride partially inhibited the rate and the extent of iron oxide

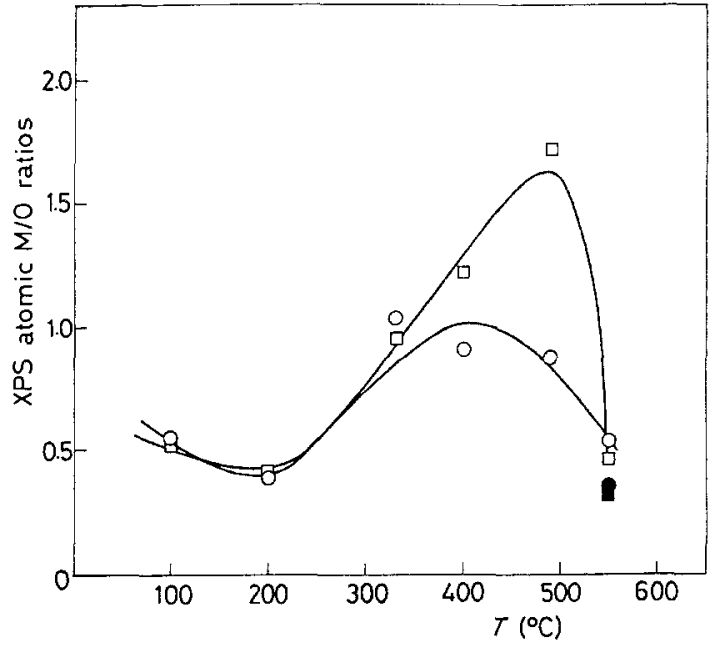

Figure 8 XPS surface composition $(\mathrm{M} / \mathrm{O}, \mathrm{M}=\mathrm{Cl}$ or $\mathrm{Mg}$ ) as a function of the pretreatment temperature: ( $\square) \mathrm{Cl},(\mathrm{O}) \mathrm{Mg}$ (symbols have the same meaning as in Fig. 6.

reduction by $\mathrm{CO}$ (Fig. 1) and substantially enhanced their mechanical strength (Table II). The working hypothesis adopted as a probable explanation of these facts is the formation of an interfacial compound between the halide and the sinter surface through complex solid-state reactions. One would expect that $\mathrm{X}$-ray diffraction patterns would be a good method for identification of that compound; however, we were unable to detect, presumably due to the intrinsic limitation of this technique, crystalline phases of size $<4 \mathrm{~nm}$. The SEM-EDAX data were, however, more conclusive. As observed in Figs $2 b$ and c, the mapping of $K \alpha$ radiation arising from chlorine and magnesium atoms indicated that magnesium was almost uniformly distributed throughout the sample, whereas chlorine was mostly concentrated within cavities or pores of the sinter particles. This is to be expected, because an important fraction of magnesium was already present in the uncoated sinter sample and only a small fraction was associated with chlorine as $\mathrm{MgCl}_{2}$. The important decrease of chlorine atoms in the sample which had been subjected to the RDI test can be interpreted as due to a partial transformation of the halide bond to the surface in $\mathrm{MgO}$ and $\mathrm{HCl}$; the latter should be present in the gas-phase. The hydrolysis reaction should be confined to the surface hydroxyl groups (or remaining chemisorbed water) in those aggregates, e.g. in $\mathrm{Fe}_{2} \mathrm{O}_{3}$.

Consequently, the $\mathrm{MgO}$ species so formed would chemically interact in the same centre where anchored, and hence no apparent migration should be expected upon thermal treatment at high temperatures. During this treatment the sample was newly heated to $550^{\circ} \mathrm{C}$ and hence a large progress of the reaction should be expected (Figs $3 \mathrm{~b}$ and $\mathrm{c}$ ).

Photoelectron spectra were also conclusive. Notice that the FWHM of the Mg $1 \mathrm{~S}$ core level signals for an $\mathrm{MgCl}_{2}$ : sinter physical mixture sample increased at higher pretreatment temperatures. Taking as reference a value of about $3.7 \mathrm{eV}$ for the FWHM of those samples pretreated at the lowest temperatures where a very low halide-sinter surface interaction should be expected, such a value becomes nearly $1 \mathrm{eV}$ below that found on the conventionally impregnated sinter 
sample. Therefore, it is indicative that strongly perturbed, or new, magnesium-containing species appeared at the sinter surface. This interpretation is still strengthened by considering the left-hand asymmetric wing of the $\mathrm{Fe} 2 \mathrm{p}_{3 / 2}$ core level peak (spectrum $\mathrm{g}^{\prime}$ ). In this latter case, iron-containing species with higher BE than that found in the samples pretreated at much lower temperatures, would be present. From these data, it is inferred that a partial transformation of the surface $\mathrm{Fe}_{2} \mathrm{O}_{3}$ species, according to the solid-state reaction $\mathrm{Fe}_{2} \mathrm{O}_{3}+\mathrm{MgO} \rightarrow \mathrm{MgFe}_{2} \mathrm{O}_{4}$, might be involved. It is finally emphasized that such a process should be mostly confined to the surface region; therefore, no significant change of magnetic susceptibility should be expected in the salt-coated sinter sample pretreated above $500^{\circ} \mathrm{C}$.

\subsection{General coating mechanism}

The above coating mechanism is also valid for the physically mixed $\mathrm{MgCl}_{2}$ : sinter samples; however, the overall description is much more complex. The untreated physically mixed $\mathrm{MgCl}_{2}$ : sinter sample contained large $\mathrm{MgCl}_{2}$ crystals which interacted little with the sinter particles, but important changes already take place at increasing pretreatment temperatures. Turning our attention again to Fig. 8, it results clear that the increasing $\mathrm{Mg} / \mathrm{O}$ ratio, and especially the $\mathrm{Cl} / \mathrm{O}$ ratio, with pretreatment temperature must be due to an increase of the surface exposure of magnesium (or chlorine) atoms in the sinter particles.

Such an increase may lie in a partial vaporization of $\mathrm{MgCl}_{2}$ from the starting $\mathrm{MgCl}_{2}$ crystallites and its further anchorage on to the free-salt sinter surface (Fig. 9). Notice that $\mathrm{MgCl}_{2}$ vapour pressure begins to be important in the temperature range 300 to $500^{\circ} \mathrm{C}\left(\mathrm{m} . \mathrm{p} .=712^{\circ} \mathrm{C}\right)$. This vaporization-adsorption phenomenon leading to better dispersed phases has recently been described for $\mathrm{MoO}_{3}$ deposited on to zeolites [17] or on to alumina [18], pretreated at much lower temperatures than the melting point of the oxide $\left(\mathrm{MoO}_{3}\right)$.

The further decrease of exposed magnesium (or chlorine) atoms above $500^{\circ} \mathrm{C}$ (Fig. 8) indicated a partial removal of these atoms from the surface through solid-state reaction with $\mathrm{Fe}_{2} \mathrm{O}_{3}$ particles, presumably assisted by the remaining surface hydroxyl groups, to form a spinel-type $\mathrm{MgFe}_{2} \mathrm{O}_{4}$ species and $\mathrm{HCl}$ gas. These $\mathrm{MgFe}_{2} \mathrm{O}_{4}$ species which, in turn, are much less reducible than $\mathrm{Fe}_{2} \mathrm{O}_{3}$ oxide itself, would be responsible for the inhibition of $\mathrm{CO}$ reduction of the salt-coated sinter samples (Fig. 1) and also for the steady increase of FWHM of the Mg $1 \mathrm{~S}$ core level (Fig. 6) in that preparation. The extent of formation of the $\mathrm{MgFe}_{2} \mathrm{O}_{4}$ species should be mostly confined to the surface region (monolayer); however, progress to a few layers in depth would be expected if sufficient $\mathrm{MgO}$ species remains available on the top-most layer (Fig. 9). The formation of spinel-type compounds at the interface of a trivalent oxide, namely $\mathrm{Al}_{2} \mathrm{O}_{3}$, when impregnated with salts of divalent metals and calcined at temperatures of $\sim 500^{\circ} \mathrm{C}$ is a well-known phenomenon exploited in catalysis to decrease the reactivity of that oxide. Notice also that the conventionally

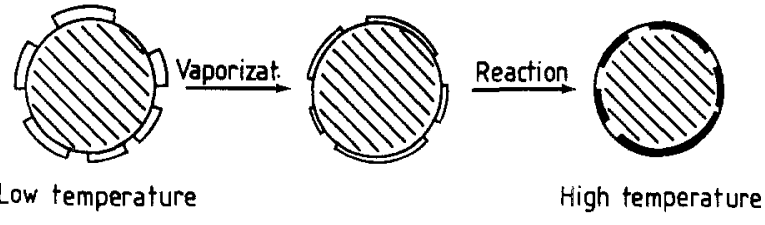

Figure 9 Proposed coating mechanism for $\mathrm{MgCl}_{2}$ : physical mixture sinter.

impregnated sinter sample pretreated at $550^{\circ} \mathrm{C}$ shows a slightly lower $\mathrm{Mg} / \mathrm{O}$ ratio, than that found on the $\mathrm{MgCl}_{2}$ : physical mixture sinter sample. This highlights the important role played by the halide dispersion on the extent of formation of the $\mathrm{MgFe}_{2} \mathrm{O}_{4}$ phase. The extent of formation of such a spinel-type structure and the further diffusion within the sub-surface layers should be greater in the conventionally impregnated samples than in the physically mixed $\mathrm{MgCl}_{2}:$ sinter preparations.

\section{Conclusion}

Coating of sinter iron ores with magnesium chloride has been shown to produce a certain inhibition of the sinter reduction at low temperature and an important improvement of mechanical strength. The same properties can already be achieved if magnesium chloride is physically mixed with the sinter iron ore. This interesting behaviour has been explained in the light of the $X$-ray photoelectron spectra and of the scanning electron micrographs combined with the energy dispersive analyses of the X-ray (EDAX) emitted by the solid. It has been shown that magnesium chloride interacts strongly at the surface of $\mathrm{Fe}_{2} \mathrm{O}_{3}$ particles and only decomposes to $\mathrm{MgO}$ (with some participation of the hydroxyl groups) at increasing temperature. The $\mathrm{MgO}$ species would then react with $\mathrm{Fe}_{2} \mathrm{O}_{4}$ to form a spinellike $\mathrm{MgFe}_{2} \mathrm{O}_{4}$ compound. Such a species, mostly confined to the surface of $\mathrm{Fe}_{2} \mathrm{O}_{3}$ particles, may be able to diffuse into the subsurface sinter layer at thermal treatments above $500^{\circ} \mathrm{C}$.

\section{Acknowledgements}

The authors would like to thank Mr C. Cubillo, Mrs M. C. Cristina and Mr A. Isidro for chemical analyses and SEM studies.

\section{References}

1. H. A. KORTMANN and O. P. BURGHARDT "Agglomeration 77" edited by K. V. S. Sastry (AIME, New York, 1977) p. 219.

2. P. W. ROLLER, Trans. ISIJ 26 (1986) 834.

3. M. T. LARREA, A. CORES, A. FORMOSO, C. CUBillo and A. GUTIERREZ, Tecnica Metalurgica 279 (1987) 5.

4. H. A. KORTMANN, W. BOCK and O. P. BURGHARDT, 4th International Symposium on Agglomeration, Toronto, Canada (1985) p. 287.

5. A Method for Measuring the Relative Reductibility (Isothermal Reactivity) of Natural and Processed Iron Ore, Fifth Draft, ISO Proposal, ISO/TC 102/SC 3/284 E (1974).

6. A Method for Determining the Low Temperature 
Desintegration Behavior of Iron Ores, Pellets and Sinters by Cold Tumbling after Static Reduction. Third draft, ISO Proposal, ISO/TC 102/SC 3/285 E (1974).

7. M. BARBER, J. A. CONNOR, M. F, GUEST, M. B. HALL, I. H. HILLIER and W. N. E. MEREDITH, J. Chem. Soc. Faraday Disc. 54 (1972) 220.

8. U. GELIUS, P. F. HEDEN, J. HEDMAN, B. J. LINDBERG, R. MANNE, R. NORDBERG, C. NORDLING and K. SIEGBAHN, Phys. Scripta 2 (1970) 70.

9. D. T. CLARK and R. WILSON, Fuel 62 (1983) 1034.

10. C. R. BRUNGLE, T. J. CHUANG and K. WANDELT, Surf. Sci. 68 (1977) 469.

11. K. YABE, K. ARATA and I. TOYoshimA, J. Catal. 57 (1979) 231.

12. G. C. ALLEN, P. M. TUCKER and R. K. WILD, Phys. Mag. B 46 (1982) 411.

13. J. E. SUEIRAS, N. HOMS, P. RAMIREZ, M. GRA-
CIA and J. L. G. FIERRO, J. Catal. 98 (1986) 264.

14. G. C. ALLEN, M. T. CURTIS, A. J. HOOPER and P. M. TUCKER, J. Chem. Soc. Dalton Trans. 14 (1975) 1525.

15. D. T. HARVES and R. W. LINTON, Anal. Chem. $\mathbf{5 3}$ (1981) 1684.

16. C. D. WAGNER, L. E. DAVIES, M. V. ZELLER, J. A. TAYLOR, R. H. RAYMOND and L. H. GALE, Surf. Int. Anal. 3 (1981) 211.

17. J. L. G. FIERRO, J. C. CONESA and A. LOPEZ AGUDO, J. Catal. 108 (1987) 334.

18. A. ARTEAGA, J, L. G. FIERRO, P. GRANGE and B. DELMON, Preprint, Petrol. Div. Amer. Chem. Soc. 32 (1987) 339.

Received 27 April

and accepted 6 July 1987 